\title{
INTERNATIONAL MATHEMATICAL CONGRESS MEDALS
}

In September, 1932, the International Congress of Mathematicians at Zurich approved the foundation of two gold medals, to be awarded at successive Congresses for outstanding achievements in mathematics. The suggestion was due to the late Dr. J. C. Fields, Research Professor of Mathematics at the University of Toronto, who wished to dispose in this way of a balance of funds remaining after the publication of the Proceedings of the Toronto Congress, 1924. The Zurich Congress appointed an

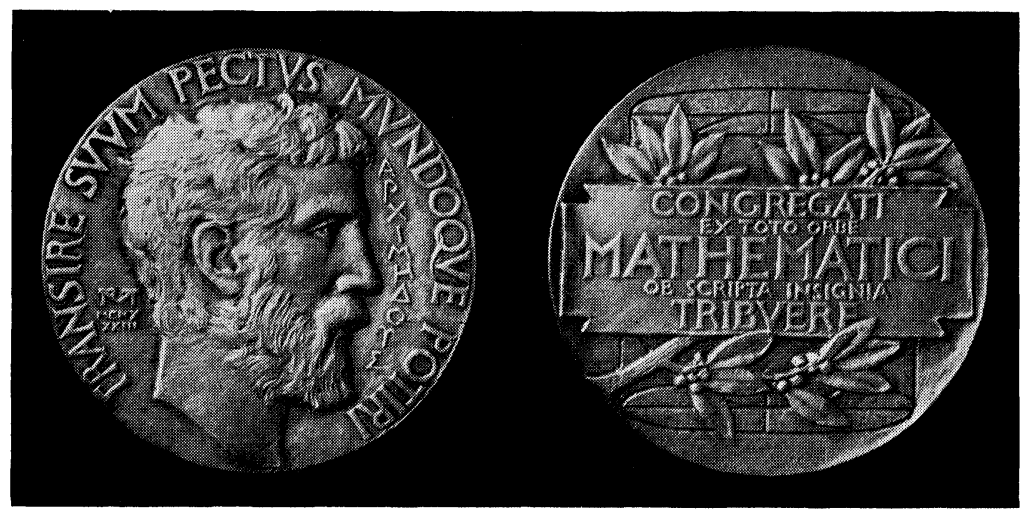

international Committee, consisting of Professors Severi (President), Birkhoff, Carathéodory, Cartan, Takagi, to decide on the awards to be made at the Congress at Oslo in 1936.

The task of designing a suitable medal was entrusted to the distinguished Canadian sculptor, Dr. R. Tait McKenzie, R.C.A., who has now completed his work.

The medal is two and a half inches in diameter. The obverse shows the head of Archimedes facing right. As there are no authentic portraits of this perhaps greatest of all mathematicians, recourse was had to the fine collection of over thirty pictures collected by Professor David Eugene Smith, and placed by him in Columbia University. They show the ideas of as many artists, ancient and modern, of what his appearance may have been. They naturally vary greatly, so the sculptor followed his own impression from reading his life and works. He shows the 
sage as a man of mature age, vigorous, with curly hair and beard, straight Greek nose and prominent brow. In the field is the word "Archimedous," (portrait) of Archimedes, in Greek capitals, and the artist's monogram, "RTM," and "MCMXXXIII."

The inscription surrounding it is, "Transire suum pectus mundoque potiri," which may be freely translated: "To transcend one's human limitations and master the universe." This appropriate quotation from the Roman poet Manilius was supplied by Professor Norwood of the University of Toronto.

The reverse has a label bearing the inscription, "Congregati ex toto orbe mathematici ob scripta insignia tribuere" which may be freely translated: "Mathematicians gathered together from the whole world honour noteworthy contributions to knowledge."

Behind the label is a laurel-branch, and cut in the background can be made out the diagram of a sphere contained in a cylinder. The determination of the relation of these two was one of the outstanding achievements of Archimedes, and the diagram was engraved on his tomb. The name of the recipient will be cut on the edge of the medal and will not interfere with the design.

The University of Toronto

J. L. Synge 